\title{
The Science and Art of Obesity
}

\section{Ariel S Torres*}

Marie France Bodyline, Int'l, Philippines

"Corresponding author: Ariel S Torres, Medical Doctor, Marie France Bodyline, Int'I, Philippines, Tel: 632917489 2168; E-mail: yeltres@yahoo.com

Received date: October 19, 2017; Accepted date: October 26, 2017; Published date: October 31, 2017

Copyright: (c) 2017 Torres AS, This is an open-access article distributed under the terms of the Creative Commons Attribution License, which permits unrestricted use, distribution, and reproduction in any medium, provided the original author and source are credited.

\begin{abstract}
Introduction: There have been so many advances in the field of Obesity. It is the objective of this article to introduce to other health professionals about the latest in science regarding obesity knowledge as well as give them a glimpse on the art of obesity management. At the same time, this article intends to update those in the field of nutrition and weight loss on the current accepted definitions, different classifications, health risk factors, causality in anatomy as well as physiology of fat hormones or adipokines, and review step-by-step the universally accepted 5 A's in treating overweight patients suffering from obesity.
\end{abstract}

Methodology: Obesity information was broken down into science and art. The science deals with exact knowledge that have been established by discoveries thru the years while the art deals with different ways by which obesity is classified and eventually managed.

Results: The science of obesity knowledge deals with the anatomy and physiology of fat hormones (adipokines) including the type of fat that they originate from (visceral, subcutaneous, superficial, and deep) as well as differentiate those that are beneficial from detrimental. The art of obesity management deals with the processes of weight loss, weight maintenance, weight regain, recidivism, and rebound phenomenon. Obesity is differentiated from adiposity and their different classifications based on the body mass index are reviewed, including how different countries use them and its history in the ICD. Culmination is the 5 a's in obesity management with concrete examples.

Conclusion: Adipokines originate from fat cells after tissue macrophages devour them when they get too large or too many. Those that originate from visceral fat, deep fat, and upper obesity tend to be detrimental while those that originate from subcutaneous fat, superficial fat, and lower obesity tend to be beneficial. Weight loss needs to be maintained for a year for it to be considered successful with long term sustainability. Obesity is having excess body fat all over that it already increases risk of disease based on health risk factors which is a combination of having a $\mathrm{BMI}>30 \mathrm{~kg} / \mathrm{m}^{2}$ and a large waist circumference based on gender and different step-up cut-offs. The 5 A's in obesity are ask, assess, advise, agree, and assist.

Keywords: Fat hormones or adipokines; Leptin; Hypertrophy and hyperplasia; Weight loss; Adiposity versus obesity; Quetlet index or body mass index; Health risk factor

\section{Introduction}

In 1967, exactly fifty years ago, the first meeting of the obesity association was held in London. This would be the start of the focus on obesity. By the 1970's, research on increasing obesity knowledge and meetings to establish obesity management were flourishing. Since that time, there have been so many advances in the field of obesity. It is the objective of this article to introduce to other health professionals about the latest in science regarding obesity knowledge as well as give them a glimpse on the art of obesity management. At the same time, this article intends to update those in the field of nutrition and weight loss on the current accepted definitions, different classifications, health risk factors, causality in anatomy as well as physiology of fat hormones or adipokines, and review step-by-step the universally accepted 5 A's in treating overweight patients suffering from obesity. But for brevity, much of the information will be summarized and detailed explanations will be omitted.

\section{Methods}

With each obesity convention being attended in various countries, and published scientific studies being read day-in and day-out, so much data has accumulated. Information on obesity was already available to the author but was needed to be vetted by further research since some have conflicting theories on the science while others have different point of views on the art.

For this literature review, obesity information was broken down into science and art. The science deals with exact knowledge that have been established by discoveries thru the years while the art deals with different ways by which obesity is classified and eventually managed. After deciding on what topics to discuss, review of existing literature was undertaken and then summarized for concise presentation.

\section{Results}

\section{The Science of Obesity Knowledge}

Origins of hormones from fatty tissue, beneficial vs. detrimental adipokines, hypertrophy (size) vs. hyperplasia (number): 
Page 2 of 6

Some hormones released by fat tissue come from fat cells being devoured by tissue macrophages in between fat cells. It is the interaction between the fat cell membrane and these tissue macrophages that produce these hormones [1]. It is a known fact in general medicine that only endocrine glands produce hormones [2]. However, by the definition that hormones are substances that are secreted in a specific organ whose effect is in another specific organ (normally remotely located from each other), then substances secreted by the "adipose tissue organ" whose receptors are in the brain, are considered hormones.

This has led to the controversy that fat tissue should be considered an endocrine gland $[3,4]$.

However, with consequent advanced research studies, it is now known that it is not always the fat cells that produce some of these hormones (unlike in other endocrine glands where their actual cells are the ones constantly producing the hormones) but rather from other cells residing in between the fat cells. So if you look at a diagram of a fat cell that is about to undergo apoptosis (Figure 1), the crown-like structures are tissue macrophages that have surrounded a single fat cell. This is in response to the fat cell membrane calling upon tissue macrophages (monocytes from blood that have resided within the general area) to eat them since they are already getting weak due to overextension (hypertrophy) [5] or too crowded already (hyperplasia) [5].

So when hypertrophy of fat cells occur (too much enlargement due to excessive triglyceride deposition) or hyperplasia (too many fat cells due to unbridled multiplication to accommodate more triglyceride deposition), some are eaten as a "survival mechanism" response to release liquid fat.

Macrophages or macro phagocytes are basically big (macro) cells (cytes) that eat or devour (phago) other cells. This is normally done to recycle their parts to create new ones (repair) or as a defense mechanism against infection (kill). In the case of fat cells, hormones are produced to signal the brain to stop overeating [6]. The problem is they also signal other organs to stop metabolizing sugar leading to insulin resistance [1].

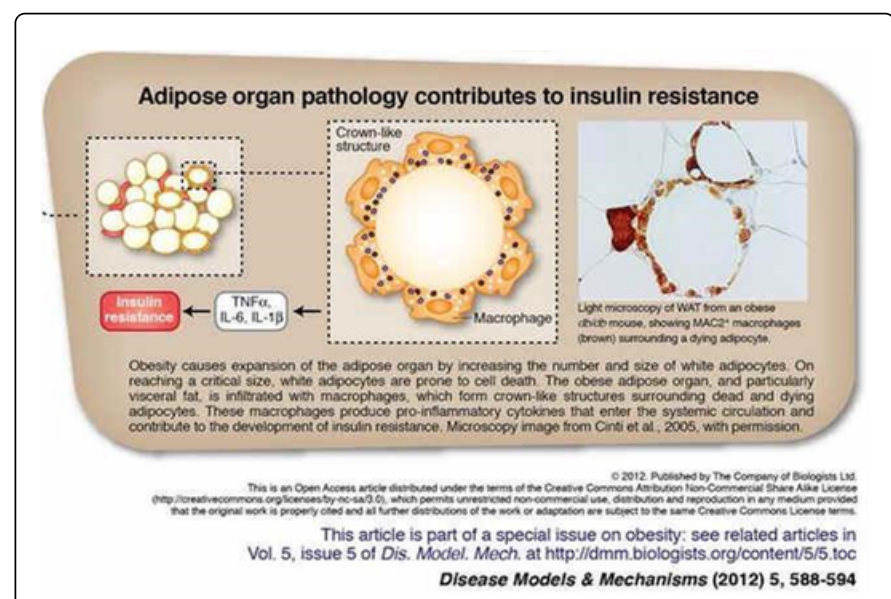

Figure 1: Adipokine production.

It must be remembered that fat cells comprise only a very, very small portion of adipose tissue since most are triglycerides and free fatty acids. But even during development of fatty tissue (embryonic formation), adipose tissue macrophages (atoms) are present even before fat cells are developed. These atoms communicate directly with regulatory $\mathrm{t}$-cells causing inflammation. It is hypothesized that stress [7] or too much central nervous system stimulation can cause these tcells to do well (recruitment model) or to do bad (conversion model).

Basically, the body is trying to stop the fat cells from increasing in size when it detects that it is over extended and filled up with liquid fat. But the inflammatory process doesn't just happen locally but also systemically leading to other diseases associated with obesity. To stop this from excessively happening, adipose tissues have mechanosensitive cells and stretch-activated ion channels [8]. With the important discovery of leptin almost two decades ago, several adipokines have since been identified. Adipocytokines come from the Greek words adipo (fat), cytos (cell), and kinos (movement) are protein signals secreted by adipose tissue. Leptin was at that time of discovery thought to be revolutionary and key to solving obesity. Everybody thought that it was going to be a miracle drug once perfected and manufactured.

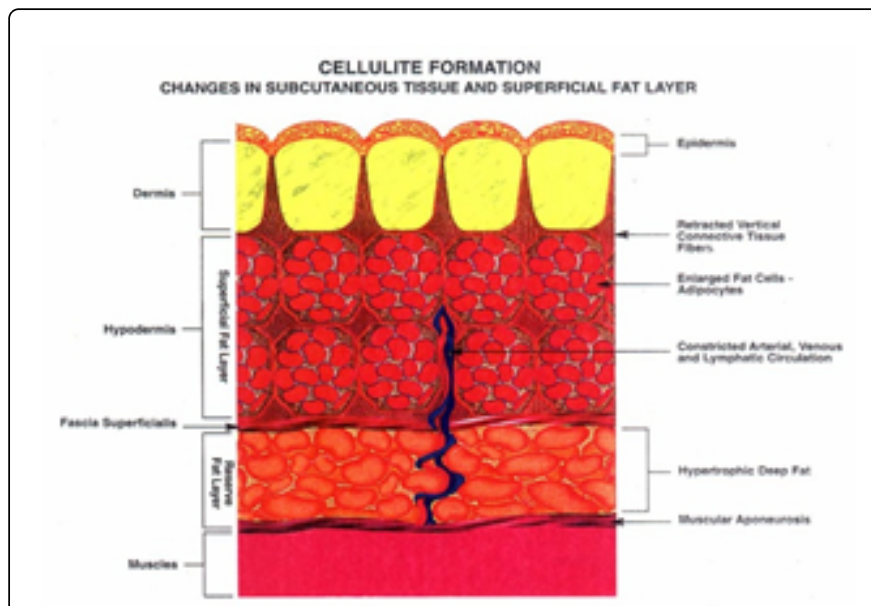

Figure 3: Deep and superficial SC fat.

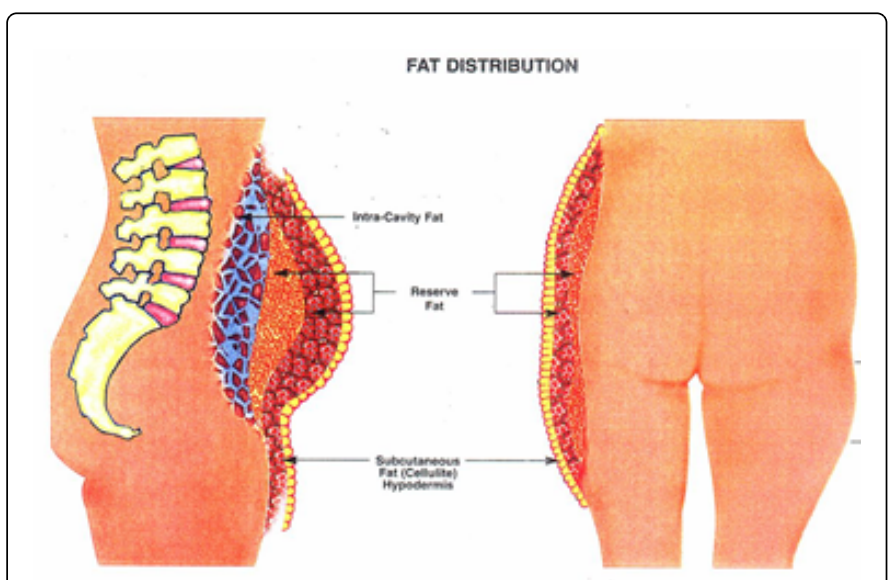

Figure 2: Visceral fat and subcutaneous (SC) fat.

But it was later found out that one can also have "leptin resistance" [9] with other harmful adipokines outweighing the beneficial 
adipokines. In fact, based on mice studies, the absence of leptin in "sham" mice leads to obesity but the abundance of leptin does not do the contrary-which is resolve obesity.

Leptin is secreted mostly by subcutaneous fat to increase satiety (only to normal levels). So even in large amounts, it does not increase satiety to produce starvation. Incidentally, leptin is poorly secreted by visceral fat.
Instead, visceral fat secrets mostly pro-inflammatory cytokines that increase insulin resistance [1]. Examples of beneficial adipokines [4] are leptin, visfatin, adiponectin and apelin. Examples of harmful adipokines [4] are tumor necrosis alpha, interleukin-6, resistin, resistin-like molecule alpha, monocyte chemo attractant protein-1, plasminogen activator inhibitor, preadipocyte factor-1, retinol binding protein 4 , and acylation stim protein.

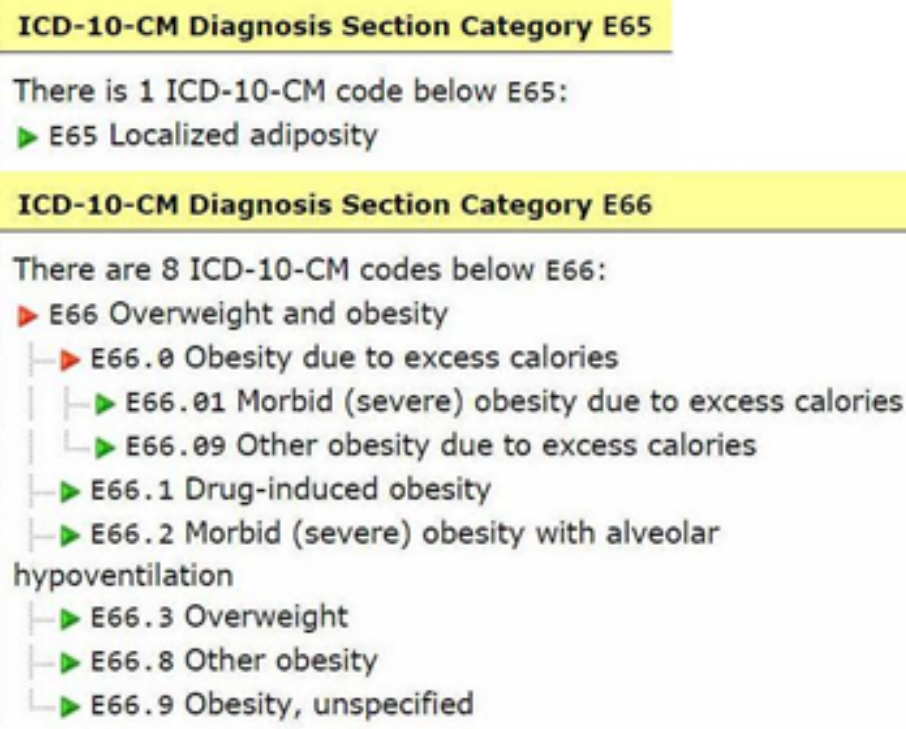

Figure 4: International classification of diseases 10 (ICD-10), endocrine section, E-65 to E-68.

It is not true anymore that only visceral fat releases harmful hormones and that subcutaneous fat releases beneficial hormones (Figures 2 and 3). It is now known that white adipose tissue (WAT) that increases in fat cell size instead of increasing in number is the type of fat that produces and releases harmful hormones. On the other hand, WAT that increases in fat cell number instead of increasing in fat cell size produces and releases beneficial hormones. So there is a need to differentiate fat hypertrophy (increase in size of fat cell) with fat hyperplasia (increase in number of fat cells).

It is also not true anymore that the number of fat cells is fixed at birth or immediately thereafter and that enlargement of WAT is due to fat cells increasing only in size. It is now known that fat cells can still increase in number due to differentiation of pre-adipocytes in response to excess food intake and lack of activity [5]. It really depends on the location of the WAT dictated by genetic variations of racial origin $[10,11]$. Visceral fat increases its volume normally by hypertrophy while subcutaneous fat increases its volume by hyperplasia.

Therefore, visceral fat produces harmful hormones while subcutaneous fat produces beneficial hormones. But recent studies done in mayo clinic [12] have even subdivided the subcutaneous fat (SCF) into two classifications: Deep SCF vs. superficial SCF and Upper Body vs. lower body SCF. Deep SCF tends to increase more by hypertrophy while superficial SCF tends to increase more by hyperplasia.

Independently, upper body SCF has a tendency to have deeper SCF while lower body SCF has a tendency to have more superficial SCF [13]. Consequently, upper body SCF releases more harmful adipokines

\section{ICD-10-CM Diagnosis Section Category E67}

\section{There are 5 ICD-10-CM codes below E67: \\ $\checkmark \mathrm{E} 67$ Other hyperalimentation \\ $>$ E67.0 Hypervitaminosis A \\ E67.1 Hypercarotinemia \\ E67.2 Megavitamin-B6 syndrome \\ E67.3 Hypervitaminosis D \\ E67.8 Other specified hyperalimentation}

ICD-10-CM Diagnosis Section Category E68

There is $1 \mathrm{ICD}-10-\mathrm{CM}$ code below E68:

$>$ E68 Sequelae of hyperalimentation while lower body SCF releases more beneficial adipokines. All of this was discovered when they observed that upper body obesity (not visceral but subcutaneous) is more intimately related to the co-morbid diseases of obesity (hypertension, hypercholesterolemia, heart disease, and diabetes). On the other hand, those with lower body obesity (buttocks and outer thighs) had a good chance of being metabolically healthy (if no abundant visceral fat is simultaneously present).

\section{The Art of Obesity Management}

Weight loss definitions, obesity as a disease, quetlet index with subsequent classifications and 5 A's of obesity management:

Weight Loss is defined as the ability to lose weight and maintain it for a year $[14,15]$. You see it's so easy to lose weight. But if you cannot maintain it, then it's as if you never lost it. So when you unintentionally gain back the weight that you intentionally lost, that's called recidivism [16]. Sometimes, you even gain more than what you lost and that's called the rebound phenomenon. Even in liposuction wherein we literally remove subcutaneous fat, if the patient cannot maintain weight before the surgical procedure was done; fat will be re-deposited in the visceral area w/c is definitely bad if not worse [17]. So what is the secret to achieving weight loss, weight maintenance?

The international classification of diseases (ICD) has its origins [18] in 1860 during the International Statistical Congress held in London. So "I-C-D" initially meant injury or cause of death. This was coined during the time of legendary nurse, florence nightingale, founder of modern nursing. Unknown to most medical professionals, obesity was already classified as a disease as early as ICD-8 that was implemented in 1965. It was listed as \#277-obesity not of endocrine in origin. This 
was followed by ICD- 9 that was created immediately after that but implemented in 1978. It was listed as \#278 but you cannot be admitted for that reason only. There must be other reasons for your obesity in order for it to be covered by the federal government. At present starting October 1, 2015 we're now using ICD-10 (Figure 4). So obesity is E65, E66, E67, or E68. It's under endocrine which is why it starts with E65 is simply localized adiposity. E66 means generally obese (and not localized anymore). E67 is due to hyper alimentation while E68 is sequelae of that.

So first and foremost, you need to differentiate adiposity versus obesity. Adiposity is defined as having excess fat locally in specific areas but doesn't increase the risk of developing metabolic disease while obesity is defined as having excess fat all over, in general, that it already causes metabolic disease. So the "old method" (Table 1) is by computing for ideal body weight (IBW). If you are $10 \%$ over your IBW, you are overweight. If you are $20 \%$ over your IBW, you have too much excess fat with a risk of suffering from obesity (meaning developing metabolic disease). So for women, the first 5 feet is $100 \mathrm{lbs}$. and every inch thereafter is $5 \mathrm{lbs}$. And for men, the first 5 feet is $106 \mathrm{lbs}$. and every inch thereafter is $6 \mathrm{lbs}$. But like I said earlier, that's the "old method".

The latest one that we use for computation in obesity is the quetlet index. It was originally formulated by Adolph Quetlet, hence the name, but the one that made it famous is ancel keys who renamed it as body mass Index or BMI (Table 2). Incidentally, Quetlet was the organizer in 1853 of what would eventually be the origins of the ICD while keys was the physiologist who did the Minnesota Starvation Experiments that led to revolutionary ideas on how we gain weight, lose weight, and then regain weight again [19]

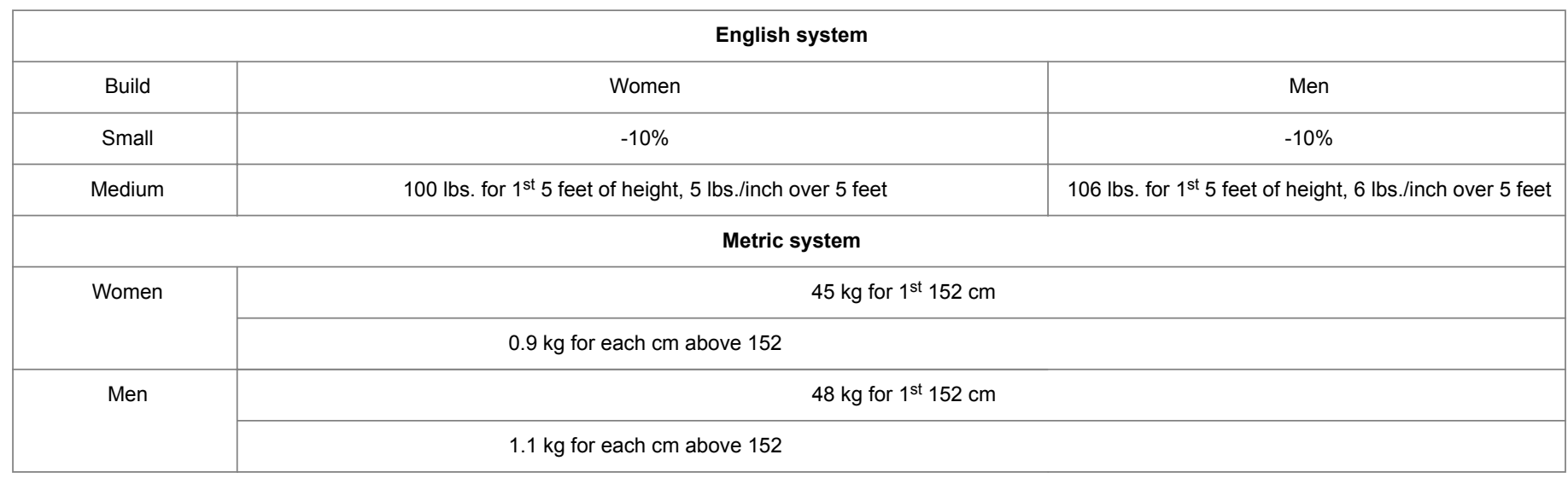

Table 1: Old method of computing for ideal weight of height.

Different regions and countries use the BMI in various ways with independent cut-offs. For Caucasians, the value considered Obese is 30 $\mathrm{kg} / \mathrm{m}^{2}$ while for Asians it is lower at $25 \mathrm{~kg} / \mathrm{m}^{2}$. Now each country has different obesity classifications. In Singapore, they only use the term "risk". So it's either you have low risk, moderate risk, or high risk. In Hong Kong, they use the term "overweight". So it's either you are overweight at risk, or overweight moderately obese, or overweight severely obese.

\begin{tabular}{|l|l|l|l|l|}
\hline \multicolumn{2}{|l|}{$\begin{array}{l}\text { Body mass index } \\
\text { (BMI) }\end{array}$} & \multicolumn{4}{l}{ Waist circumference (cm) } & $>88$ \\
\hline Females & $<70$ & $<80$ & $71-88$ & $81-102$ \\
\hline Males & $18.5-24.9$ & Very low risk & Low risk & Medium risk \\
\hline Normal & $25.0-29.9$ & Low risk & Medium risk & High risk \\
\hline Overweight & $30.0-34.9$ & Medium risk & High risk & Very high risk \\
\hline Obese I & $35.0-39.9$ & High risk & Very high risk & Very high risk \\
\hline Obese II & $\geq 40.0$ & Moderately high risk & Very high risk & Very high risk \\
\hline Obese III & 2 & &
\end{tabular}

Table 2: Health risk factors (combination of BMI and WC).

In Japan, once you are above normal, then you are automatically obese and they just grade you as either level 1, level 2, level 3, or level 4.
In the US, the center for disease control or CDC gives percentile similar to what we use in pediatrics. And the age is important not unlike in other BMI classifications. They even differentiate between men and women. In the others, they don't. So if you are less than 5 Percentile, you are undernourished while if you are over 95 percentile, you are over nourished.

Lately, it has been noted that the waist circumference and waist-hip ratio is more pathognomonic and more specific in determining excess visceral fat $[20,21]$. This was correlated with CT scan and MRI results (ergo more prone to develop and suffer from obesity). So what they did was the next best thing which is to mix the BMI and waist circumference. And they came out initially with a table wherein both are actually used. However, the cut-offs for the waist circumference was only one for both females $(80 \mathrm{~cm})$ and males $(90 \mathrm{~cm})$. The latest one that we are using right now Table 2 has two cut-offs for both females $(70 \mathrm{~cm}$ and $88 \mathrm{~cm})$ and males $(80 \mathrm{~cm}$ and $102 \mathrm{~cm})$.

So for example a male with a waist circumference of more than $102 \mathrm{~cm}$ with a BMI of 32 kilograms per meter squared would have a very high risk of developing diseases associated with metabolic syndrome like hypertension, hypercholesterolemia, heart disease, and diabetes. But if he can lose some visceral fat and therefore decrease his waist circumference and at the same time lose weight and therefore decrease his body mass index, then he would move to the left and upwards of the table-improving his classification to medium risk.

So there are 5 A's in obesity management [22]. The first A is ask. You have to ask permission to discuss a patient's weight because weight is a 
very sensitive issue for patients suffering from obesity. So you have a sit down with the patient. Then ask, "may I talk to you about your weight?". If she replies, "Yes it's okay to talk about my weight. I'm glad you asked", then that's a good thing (click). You then follow it up and say, "I'd like to offer my help. Is it okay if I help?" Hopefully, she says, "yes please, I would appreciate any help you can offer." The second A is assess. You need to determine if there are any health conditions that led to excess fat or the reverse, if excess fat has led to any health condition. So you normally do a complete physical exam. And you also draw blood to determine if she has diabetes where excess sugar is stored as fat, or hypothyroidism where metabolism slows down, or rheumatoid factor which led to immobility, etc. The third A is Advise. So you tell the patient, "now that we know your health situation, let's make plans on improving it. The fourth A is Agree. You have to agree on goals that are S-M-A-R-T [23]. So they should be specific, measurable, achievable, rewarding, and timely. And the fifth A is assist. Facilitators are there for motivation and support to confront barriers that can be challenging. So those are the 5 A's in obesity management and without one of them, there are less chances of success.

\section{Discussion}

Adipokines originate from fat cells after tissue macrophages devour them when they get too large or too many. This is only one of the ways that adipokines are produced. But other experts believe that all, if not majority, of adipokines are produced by the fat cells themselves per se and not as a consequence of the adipose tissue macrophages present within the adipose tissue that reside in between fat cells.

Those that originate from visceral fat, deep fat, and upper obesity tend to be detrimental while those that originate from subcutaneous fat, superficial fat, and lower obesity tend to be beneficial. This is still an on-going research being done in mayo clinic wherein they noted that location of fat predilections dictate the abundance or lack thereof by certain specific adipokines. The initial controversy that needs to be tackled is to agree upon on which type of adipokine is beneficial from detrimental. This creates an additional Issue on whether a specific reaction, for example inflammation, is considered good or bad. after which, the next decision is to agree on which fat cells depending on their location as well as how they increase (either by size or by number) secretes good or bad fat hormones.

Weight loss needs to be maintained for a year for it to be considered successful with long term sustainability. It was noted that when you lose weight, your body will react to it by letting you regain weight in order to maintain homeostasis. But they discovered that this defense reaction lasts only for several months. So if you started out at a certain weight before you started losing weight, your body will try to go back to that weight. But after a year, this target weight will be forgotten and your body will now try to adapt to your new lesser weight. And the weight needs to be substantial which is another issue. Others believe that losing $10 \%$ of your original weight is the cut-off. Others believe that it should be bigger at $20 \%$ for morbidly obese with a BMI $>40$ $\mathrm{kg} / \mathrm{m}^{2}$ while others believe that even $5 \%$, especially those that are simply overweight with a BMI between $25-30 \mathrm{~kg} / \mathrm{m}^{2}$, is enough to produce a reduction in health risk factors of developing diseases.

Obesity is having excess body fat all over that it already increases risk of disease based on health risk factors which is a combination of having a $\mathrm{BMI}>30 \mathrm{~kg} / \mathrm{m}^{2}$ and a large waist circumference based on gender and different step-up cut-offs. Others believe that BMI should totally be removed in the assessment of obesity. They believe that simply using the waist circumference is a better predictor of possible risks in developing disease. So as a compromise, they were combined and tabulated for easy use (Table 2). If you have a high BMI but your WC is low, then you have the same risk of someone that has a low BMI but high WC. Having a low BMI and WC puts you at the lowest risk while having a high BMI and WC put you at the highest risk.

The 5 A's in obesity are ask, assess, advise, agree, and assist. These 5 A's are actually an adaptation for those with other diseases and/or addictions. For example, there are 5 A's on stopping smoking for those addicted to cigarettes while there are 5 A's on decreasing cardiovascular diseases for those who love to eat fatty food yet love to lie or sit down most of the time. So this is nothing new in the medical community. Yet, very few know about it. And in those few that know about it, it is also rare that they follow it. Most doctors don't follow these suggestions which are a prerequisite for a successful program of obesity management. They always want to cure the disease (diabetes, hypertension, heart disease, and hyperlipidemia) but don't give advice on obesity which is part of the cause of the disease. Doctors have forgotten the age old saying, "an ounce of prevention is better than a pound of cure."

\section{Conclusion}

Of all topics in clinical medicine, it has been the burden of Obesity to prove that it is a chronic disease that deserves the proper attention that is being given to others. Time and time again, medical doctors do not pay attention to maybe one of the causes of most diseases. In turn, obesity literature has not been vetted on their veracity. There are lots of controversies regarding what is fact and what is fiction regarding obesity knowledge and obesity management. The science of obesity needs to be validated and discoveries disseminated properly. On the other hand, the art of obesity is still up for debate on which management is best but certain standards and methods have long been established and is currently being used uniformly. Unless obesity is given its due importance, it will continue to rise world-wide, even in third world countries. No wonder most obesity experts have already decided this early that the 2025 global target of halting the rise in obesity incidences is doomed to fail.

\section{References}

1. Cinti S (2012) The adipose organ at a glance. Disease Models and Mechanisms 5: 588-594.

2. Guyton A (1986) Textbook of medical physiology (7thEd).

3. Melmed S, Polonsky K, Reed Larsen P, Kronenberg H (2015) William's Textbook of Endocrinology (13thedn). Elsevier/Saunders, Philadelphia.

4. Isaacs, S (2007) The leptin boost diet: Unleash your fat-controlling hormones for maximum Wweight loss. Ulysses Press, Berkeley California.

5. Jo J, Gavrilova O, Pack S, Jou W, Mullen S, et al. (2009) Hypertrophy and/or Hyperplasia: Dynamics of adipose tissue growth. PLOS Computational Biology 5: e1000324.

6. Isaacs S (2012) Hormonal balance: Understanding hormones, weight, and your metabolism (3rdedn). Bull Publishing Company, Boulder Colorado.

7. Kipnis J, Gadani S, Derecki N (2012) Procognitive properties of T-cells. Nat Rev Immunol 12: 663-669.

8. Yuan Y, Gao J, Ogawa R (2015) Mechanobiology and mechanotherapy of adipose tissue: Effect of mechanical force on fat tissue engineering. Plast Reconstr Surg Glob Open 3: e578.

9. Myers JM, Leibel R, Seeley R, Schwartz M (2010) Obesity and leptin resistance: Distinguishing cause from effect. Trends Endocrinol Metab 21: 643-651. 
10. Bouachard C (1997) Genetic determinants of regional fat distribution. Hum Reprod 1: 1-5.

11. Wang T, Ma X, Peng D, Zhang R, Sun X, et al. (2016) Effects of obesity related genetic variations on visceral and subcutaneous fat distribution in a chinese population. Sci Rep 6: 20691 .

12. Jokela M, Hamer M, Singh MA, Batty GD, Kivimaki M (2014) Association of metabolically healthy obesity with depressive symptoms: Pooled analysis of eight studies. Mol psychiatry 19: 910-914.

13. Singh P, Somers VK, Romero CA, Sert-Kuniyoshi FH, Jensen M, et al. (2012) Effects of weight gain and weight loss on regional fat distribution. Am J Clin Nutr 96: 229-233.

14. Wing RR, Hill JO (2001) Successful weight loss maintenance. Annu Rev of Nutr 21:323-341.

15. Iepsen EW, Lundren J, Holst JJ, Madsbad S, Torekov SS (2016) Successful weight loss maintenance includes long term increased meal responses of GLP-1 and PYY3-36. Eur J Endocrinol 174: 775-784.

16. Turk MW, Yang K, Hravnak M, Sereika S, Ewing L, et al. (2009) Randomized clinical trials of weight loss maintenance: A review. J Cardiovasc Nurs 24: 58-80.

17. Hernandez TL, Kittelson JM, Law CK, Ketch LL, Stob NR (2011) Fat distribution following resuction lipectomy: Defense of body fat and patterns of restoration. Obesity 19: 1388-1395.
18. Topaz M, Shafran-Topaz L, Bowles K (2013) ICD-9 to ICD-10: Evolution, revolution, and current debates in the Unites States. Perspect Health Inf Manag 10: 1d.

19. Kalm L, Semba R (2005) They starved so that others be better fed: Remembering ancel keys and the minnesota experiment. J Nutr 135 1347-1352.

20. Dasgupta S, Hazra SC (1999) The utility of waist circumference in assessment of obesity. Indian J Public Health 43: 132-135.

21. Ross R, Rissanen J, Hudson R (1996) Sensitivity associated with the identification of visceral adipose tissue levels using waist circumference in men and women: Effect of weight loss. International J Obes 20: 533-538.

22. Vallis M, Piccinini-Vallis H, Sharma A, Freedhoff Y (2013) Modified 5 as: Minimal intervention for obesity counseling in primary care. Can Fam Physician 59: 27-31.

23. Osunlana A, Asselin J, Anderson R, Ogunleye A, Sharma A (2015) 5A's team obesity intervention in primary care: Development and evaluation of shared decision-making weight management tools. Clinical Obesity 4: $219-225$. 